\title{
ENTRE SANGRADORES E DOUTORES: PRÁTICAS E FORMAÇÃO MÉDICA NA PRIMEIRA METADE DO SÉCULO XIX
}

\author{
TÂnia Salgado Pimenta*
}

\begin{abstract}
RESUMO: Durante a primeira metade do século XIX, a atividade do sangrador (fundamental na terapêutica do período) passou por mudanças relacionadas à progressiva organização dos médicos sobretudo por meio da institucionalização de sua educação com a criação de faculdades. Estes lutavam pelo monopólio das atividades terapêuticas, buscando desautorizar e desqualificar a prática da sangria por aqueles que não fossem médicos e/ou cirurgiões formados na academia. $\mathrm{O}$ artigo pretende analisar tais mudanças, focando a atenção na relação entre os sangradores e os médicos acadêmicos e a crescente preocupação destes com a higienização.
\end{abstract}

Palavras-chave: História da medicina. Sangradores. Médicos. Brasil. Século XIX.

\section{BLEEDERS AND PHYSICIANS: \\ PRACTICES AND MEDICAL EDUCATION \\ IN THE FIRST HALF OF THE XIX ${ }^{\mathrm{TH}}$ CENTURY}

ABSTRACT: During the first half of the XIX ${ }^{\text {th }}$ Century, the activity of bleeder (crucial in the therapeutics of the period) experienced changes related to the gradual organization of the physicians - above all through the institutionalization of their education with the creation of medical schools. They fought for the monopoly of the medical care activities, and searched to make illegal and to disqualify the practice of bleeding exercised when practiced by anyone who wasn't a doctor and/or a surgeon graduate in the academy. This paper intends to analyze such changes, focusing on the relation between bleeders and doctors and the increasing concern of these for hygiene.

Key words: History of medicine. Bleeders. Physicians. Brazil. XIX ${ }^{\text {th }}$ Century.

\footnotetext{
* Mestre em História Social do Trabalho e doutoranda em História Social, ambas pela Universidade Estadual de Campinas (UNICAMP).E-mail: spimenta@domain.com.br
} 
$E$ stamos acostumados a reconhecer nos médicos as legítimas autoridades em assuntos de doença e de terapia. Quando recorremos a outros profissionais da área da saúde, recomenda-se que um médico acompanhe o tratamento. Mesmo correntes terapêuticas que se baseiam em outros tipos de racionalidade, como a homeopatia e a acupuntura, foram incorporadas pela medicina acadêmica (Luz, 1988).

Mas essa hegemonia é recente. Ao analisarmos o exercício das práticas médicas, durante as três primeiras décadas do século XIX, deparamo-nos com uma situação bem diferente. Junto com licenças para médicos, cirurgióes e boticários, havia para sangradores, parteiras e curandeiros. Todos que quisessem exercer alguma atividade terapêutica teriam liberdade para isso, caso conseguissem uma autorização concedida pela Fisicatura mor, que era o órgão do governo responsável pela regulamentação e fiscalização das práticas de cura.

Neste artigo, pretendemos analisar as mudanças nas relações entre os médicos acadêmicos e terapeutas populares, focando a atenção no esforço dos primeiros para conseguir o monopólio das atividades médicas durante a primeira metade dos Oitocentos. Esforço que passava pela organização dos médicos em torno de associações, de periódicos especializados e da Faculdade, criada em 1832, que contribuiu para a adoção de uma nomenclatura e de concepçôes de doença e cura mais distantes das populares. Nesse contexto, identificamos a tentativa, embasada no discurso higienista, de desqualificar e desautorizar os conhecimentos e as práticas de terapeutas populares como os sangradores. ${ }^{1}$

\section{Práticas de cura autorizadas}

Desde meados do século XV, elaboravam-se regimentos para os ofícios relacionados às "artes de curar" que valiam para todo o império português. Ao longo do tempo, foram sendo modificados e, em 1808, com a transferência da Corte para o Brasil, foi recriada, com sede no Rio de Janeiro, a Fisicatura mor, que existiu até 1828. Dessa forma, a maior parte dos documentos relativos ao processo de solicitação de licença encontra-se no Arquivo Nacional do Rio de Janeiro. Trata-se de pedidos de licença, de autos de exame, de registros das licenças e de atestados e abaixo-assinados de quem fazia uso do serviço dos terapeutas, entre outros documentos. 
O leque de ofícios reconhecidos pelo governo era bastante amplo, mas cada um tinha as suas atividades bem delimitadas, fazendo parte da hierarquia adotada pela Fisicatura mor. Os médicos, que podiam prescrever remédios, os cirurgiōes, que tratavam de "moléstias externas", e os boticários, que manipulavam e vendiam os medicamentos, constituíam o grupo mais prestigiado. Os sangradores, que podiam sangrar e aplicar sanguessugas e ventosas, as parteiras, que ajudavam as mulheres a dar à luz, e os curandeiros, que podiam cuidar de doenças "leves" e aplicar remédios feitos com plantas medicinais nativas, desempenhavam atividades menos consideradas. Incluíam-se aí os licenciados a tratar somente de alguma moléstia específica, como embriaguez e morféia.

No entender dessa instituição, as práticas terapêuticas que poderiam ser legalizadas eram as que podiam ser enformadas nas categorias já estabelecidas, cujas atividades eram bem delimitadas. Porém, muitas vezes, os terapeutas não restringiam as suas atividades aos limites postos oficialmente. Conforme verificamos por meio de denúncias recebidas pela Fisicatura mor, parteiras prescreviam remédios e curandeiros, muitas vezes, atendiam pessoas a quem os médicos não tinham conseguido curar. As denominações de sangrador, parteira e curandeiro não abrangiam a diversidade das práticas de quem era rotulado como tal. Por isso, freqüentemente lançamos mão de outra categoria: terapeutas populares. Desse modo, opta-se por um termo que abranja e esmaeça os limites entre os ofícios citados e consideram-se, principalmente, as posições sociais subalternas dos terapeutas: mulheres, escravos, forros, africanos. A distribuição das cartas de autorização ocorria de acordo com as diferenças social e econômica existentes na sociedade. E a outorga dos títulos, por sua vez, reafirmava o maior ou menor prestígio das pessoas que os recebiam.

Não obstante a hierarquização, a oficialização das práticas de cura populares significava o reconhecimento desse saber como legítimo, o que permitia a inclusão dos terapeutas populares entre as pessoas autorizadas a exercer alguma atividade de cura. Isso se dava no contexto de uma sociedade na qual as relações eram traçadas por intermérdio de redes de dependências pessoais que se construíam a partir de favores, lealdades, obediência e proteção, materializadas muitas vezes em nomeações a cargos públicos, em privilégios a alguma pessoa num processo burocrático. Essas dependências abrangiam desde a posição mais elevada da hierarquia social, na pessoa do rei ou imperador, até as mais inferiores, como as que envolviam os 
funcionários da Fisicatura mor, que podiam facilitar a obtenção da licença para um curandeiro de seu conhecimento (Graham, 1997).

A Fisicatura mor esforçava-se em fazer valer a sua autoridade e tentar garantir as prerrogativas dos que se tinham oficializado, sobretudo daqueles cujas atividades eram as mais valorizadas. Apesar disso, o número de licenças concedidas aos terapeutas populares foi muito pequeno, destoando do constatado por intermédio de outras fontes, como os relatos de viajantes, os periódicos e as correspondências entre autoridades, que fazem referência à presença desses terapeutas disseminada pelo Brasil. Em geral, curandeiros, sangradores e parteiras oficializavam as suas atividades quando tomavam conhecimento da proximidade da fiscalização (às vezes, em virtude de alguma denúncia) ou quando viam na obtenção de uma licença uma forma de se sobressair entre os concorrentes, como nos centros urbanos.

\section{Os sangradores}

No caso dos sangradores havia outro motivo que os levava a pedir autorização: se quisessem trabalhar em navios, deveriam apresentar uma licença da Fisicatura mor. Esses homens eram fundamentais e, muitas vezes, o único recurso terapêutico para quem estivesse doente. Além das embarcações, eles desempenhavam uma função muito importante dentro da maioria dos métodos terapêuticos. Para a medicina acadêmica, na Europa ocidental, a sangria fazia parte da terapêutica, que incluía ainda sudoríficos, purgantes, eméticos, evacuativos e dietas, e tentava livrar o organismo dos humores em excesso que atrapalhavam o perfeito funcionamento do corpo (Pimenta, 1997). Provavelmente, as visões cosmológicas dos sangradores em sua maior parte africanos e descendentes de africanos - concediam elementos espirituais às doenças (Karasch, 1987; Slenes, 1991/ 1992). A utilização da sangria entre comunidades indígenas e em setores populares europeus também se baseava em crenças semelhantes (Santos Filho, 1977; Silva, 1993).

Mesmo tão importante para a medicina acadêmica, esse ofício era relegado aos grupos mais subalternos da sociedade: escravos e forros, que constituíam $85 \%$ dos pedidos de oficialização. Pessoas em posiçôes sociais mais elevadas só pediam licença de sangrador porque esta era requisitada a quem quisesse se oficializar como cirurgião. "Sarjar, lançar ventosas e sanguessugas, e tirar dentes" eram 
consideradas atividades "mecânicas" e, por isso, próprias de cativos e alforriados. ${ }^{2}$ Dessa forma, não surpreende que a maioria dos sangradores oficializados fosse africana (64\%). Com isso, podemos facilmente imaginar que deviam ser muitos os africanos que voltavam à África e retornavam ao Brasil cuidando dos novos escravos. A vantagem em se levar africanos como sangradores nos navios negreiros residia na probabilidade de se comunicarem mais facilmente por meio de uma língua franca, graças às semelhanças lingüísticas entre os bantu, que predominavam entre os escravos na região centro-sul do Brasil (Slenes, 1991/1992).

Para os africanos recém-capturados, o apoio que encontravam nos sangradores africanos também dizia respeito à identificação com partes de seu complexo cultural, como pressuposições básicas sobre o parentesco e visões cosmológicas. Os escravos de origem bantu, por exemplo, compartilhavam a idéia de que o desequilíbrio, o infortúnio e a doença seriam causados pela ação malévola de espíritos ou de pessoas, freqüentemente por meio da bruxaria ou da feitiçaria (Slenes, 1991/1992; Thompson, 1984).

Muitos escravos eram mandados por seus senhores ao mestre régio dos sangradores para aprenderem o ofício e renderem bons tostôes. Mas a maioria aprendia com os vários sangradores que possuíam lojas pelas cidades. E, por intermédio desse aprendizado, relações eram constituídas ou reforçadas, o que deve ter contado para que os sangradores africanos, sobretudo os forros, que iam à África retornassem ao Brasil. Além das lojas, muitos dos sangradores escravos exerciam a sua arte de forma ambulante pelas ruas e praças da Corte, como negros de ganho. E, assim como uma boa parte dos escravos da cidade do Rio de Janeiro, deveriam fornecer ao senhor um jornal previamente estipulado (Chalhoub, 1990; Cunha, 1985; Karasch, 1987).

A obediência ou não às determinações da Fisicatura mor dependia da situação em que estavam trabalhando. Às vezes, atuavam estritamente sangrando, executando o que o médico ou cirurgião havia determinado. Nesses casos, a proximidade de pessoas que podiam denunciá-los pode ter contribuído para que se oficializassem. Contudo, quando os sangradores constituíam os únicos terapeutas a tratar de alguém, faziam às vezes de curandeiros e, estando distantes de quem pudesse denunciá-los, não se preocupariam em obter licença ou carta quer para sangrador quer para curandeiro. E, mesmo que tivessem carta de sangrador, longe da fiscalização, nada os obrigaria a que se ativessem a apenas sangrar. 
Em meados de 1826, o debate sobre a extinção da Fisicatura mor iniciou-se na Câmara dos Deputados, quando a comissão de saúde pública, após ter examinado "os numerosos requerimentos dos cidadãos brasileiros, em que se queixam das vexaçôes, arbitrariedades, e extorsōes dos juízos da provedoria-mor da saúde, e fisicatura mor do império", propunha um projeto de lei pelo qual seriam abolidos esses juízos. ${ }^{3}$ Isso ocorreu num contexto de crescimento da voga antilusitana no período, em que a instituição passou a ser identificada com os interesses portugueses (Holanda, 1982; Machado et al., 1978). Além disso, desde 1826, vinha se construindo certa autonomia dos cirurgiōes e médicos ligados às Academias Médico-Cirúrgicas da Bahia e do Rio, quando essas passaram a poder conceder cartas de cirurgião e de cirurgião formado. ${ }^{4}$

Poucos anos depois de sua extinção, em 1828, a Fisicatura mor foi caracterizada como um "tribunal monstruoso, tão nocivo a nossa ciência, e aos interesses da humanidade" pela Sociedade de Medicina do Rio de Janeiro, onde se concentravam os médicos mais atuantes na organização das instituições médicas. ${ }^{5}$ Podemos supor, então, que a falta de apoio de tais médicos pode ter concorrido para o fim do órgão, cujas funções relativas à autorização e fiscalização do exercício de curar ficaram sem substitutos. ${ }^{6}$ Somente em 1830 é que essa questão volta a ser tratada, no Rio de Janeiro, com a determinação da Câmara Municipal de que: "Nenhum Facultativo, Boticário, Parteira, ou Sangrador poderá curar, e exercer Sua Arte Dentro do Município sem ter apresentado suas Cartas na Câmara onde ficarão registradas (...)" ${ }^{7}$ Assim, apenas quem já tinha a sua carta é que deveria se dirigir à Câmara para registrá-la. Nesse período, quem já não as possuía estaria exercendo um ofício ilegalmente. Mais que isso: os curandeiros nem eram citados. Portanto, depois de 1828, essa categoria sequer era considerada.

No final de 1832, a situação tornou-se obscura também para os sangradores. Com a lei que transformava as Academias MédicoCirúrgicas em Faculdades de Medicina, estas passavam a expedir os títulos de doutor em medicina, de farmacêutico e de parteira - a partir de então o título de sangrador não seria mais concedido. ${ }^{8}$

Essas mudanças em relação à autorização do exercício das artes de curar eram acompanhadas aos poucos tanto pelos órgãos que deveriam executá-las, quanto pelos próprios terapeutas que deveri- 
am se submeter a elas. Vários sangradores dirigiram-se à Câmara por essa época para requerer licenças, mas nem esta instituição nem qualquer outra assumiu a responsabilidade de concedê-las. ${ }^{9}$

A partir do começo da década de 1830, os médicos passaram a externar desconfianças acerca das habilidades dos sangradores. Tal atitude estava relacionada à progressiva organização da corporação médica e da luta desta categoria pelo monopólio das práticas de cura. Um importante passo nesse sentido foi a criação das Faculdades de Medicina na Bahia e no Rio de Janeiro, que uniu os ofícios de médico e de cirurgião. Nesse período, também foram criados a Sociedade de Medicina do Rio de Janeiro (1829) e alguns periódicos especializados como o Propagador das Ciências Médicas (1827-1828), o Semanário de Saúde Pública (1831-1833), o Diário de Saúde (1835-1836), a Revista Médica Fluminense (1835-1841) e a Revista Médica Brasileira (1841-1843).

Em 1832, a Sociedade de Medicina mandou um ofício ao ministro de Estado dos Negócios do Império solicitando que interviesse junto às autoridades para fazer cumprir, efetivamente, as leis que existiam sobre os barbeiros, pois acontecia

serem franca, e impunemente exercidas estas profissões [sangrador e dentista - associados ao ofício de barbeiro] não só por homens livres, ainda que ignorantes, e sem princípios, como também por Escravos ainda boçais, por comissão de seus Senhores, dando assim lugar a inconvenientes bem desagradáveis, e mui tristes, que se tem feito reparáveis nestes últimos tempos, sem que por ora tenha havido exemplo algum de punição contra os infratores das Leis que existem. ${ }^{10}$

$\mathrm{Na}$ década seguinte, continuava o processo de desqualificação dos sangradores:

(...) de ordinário estúpidos africanos, que às vezes nem sabem expressarse, principiam aprendendo a sangrar sobre talos de couves! e depois armados de pontiagudas lancetas, levam o seu ferro, muitas vezes assassino, sobre partes bastante delicadas, entremetendo-se a fazerem as mais difíceis e perigosas sangrias: então, despidos dos mais símplices conhecimentos, e com princípios tais, produzem os males de que quotidianamente somos impassíveis espectadores (...). ${ }^{11}$

Contudo, independentemente da legislação em vigor e da vontade dos médicos, os sangradores continuaram em atividade. Os anúncios de seus serviços não deixaram de ser publicados nos perió- 
dicos, assim como a venda das próprias sanguessugas, até meados da década de 1850 , pelo menos. ${ }^{12}$ A condenação ao trabalho dos sangradores estava inserida no discurso higienista, encontrado com frequiência nas teses defendidas pelos alunos de medicina a partir da década de 1840. Os acadêmicos identificavam os problemas e prescreviam os comportamentos mais adequados às grávidas, aos trabalhadores, aos escravos, aos intelectuais. Os conselhos abarcavam desde a alimentação e os exercícios até o vestuário e a habitação. Também cobravam das autoridades a limpeza das ruas e praças públicas, o cuidado com a venda de alimentos, a proibição de enterros dentro de igrejas. Os autores consideravam a presença do Estado muito aquém da almejada no que tange a problemas sanitários e à fiscalização do exercício médico - questóes, na prática, consideradas secundárias por um governo às voltas com as dificuldades de consolidação do Estado nacional. Ainda assim, este teve um papel importante, criando e/ou mantendo a Academia Médico-Cirúrgica/Faculdade de Medicina, a Academia Imperial de Medicina (1835) e alguns periódicos especializados.

\section{A relação médicos/sangradores no hospital}

Se a luta dos médicos pelo monopólio das atividades terapêuticas era dura na sociedade, também não era fácil dentro do hospital, em particular, embora tenha se saído mais profícua. Analisando o mais importante do período - o da Santa Casa da Misericórdia do Rio de Janeiro -, observamos que, apesar dos conflitos com a direção, nesse ambiente, os médicos tiveram mais condiçôes de impor, aos poucos, as regras da higiene.

De acordo com Karasch (1987, p. 203), alguns escravos aprendiam aí todos os aspectos dos cuidados hospitalares. De acordo com os registros da Fisicatura mor, alguns sangradores praticavam na Misericórdia, aplicando remédios também, antes de pedir a licença. ${ }^{13}$ Mas, durante o processo de medicalização do hospital, o espaço para atuação dos sangradores diminuiu, sobretudo com a presença dos alunos da Academia Médico-Cirúrgica, depois Faculdade de Medicina. Estes podiam executar tarefas consideradas pequenas demais para médicos ou cirurgiōes, ao mesmo tempo em que as tiravam das mãos de pessoas pouco capacitadas até mesmo para tais atividades.

Desde a sua criação, em 1813, algumas aulas da Academia Médico-Cirúrgica do Rio de Janeiro eram ministradas na Santa Casa. Até o final da década de 1820, o número de professores e de cursos 
manteve-se estável. A partir de então, a presença da Academia fez-se mais forte, mudando o cotidiano do hospital. Anualmente, o governo expedia ordens para que fossem cedidos alguns enfermos ou uma enfermaria, escolhidos pelo professor, para serem estudados e tratados por sua turma. A botica também estaria à disposição para o estudo sobre os medicamentos. O hospital passava a ser, de fato, um lugar de ensino - e fundamental no processo de transformação do exercício terapêutico. Tais mudanças não se deram sem conflitos com a irmandade que o administrava, mas foram sendo contornados ao longo do período estudado. ${ }^{14}$

Cada vez mais, admitiam-se alunos que pediam para trabalhar como pensionistas (estagiários) sob orientação dos médicos e cirurgiōes. Tentava-se estabelecer um certo nível de conhecimento do saber e da linguagem acadêmicos, procurando-se aceitar apenas os estudantes que estivessem cursando o $3^{\circ}$ ano em diante. ${ }^{15}$ Mesmo as aulas teóricas foram ministradas, por algum tempo, no hospital. Dessa forma, a Academia/Faculdade estava proporcionando um número crescente de cirurgiões e de médicos disponíveis e com intenção de trabalhar no hospital para adquirir mais experiência.

Nesse contexto, o regimento de 1827 do hospital da Santa Casa chamava atenção para a conveniência de estudantes mais adiantados sangrarem. Vinte anos depois, isso se havia tornado obrigação: "É da obrigação de um e outros [um pensionista interno e dois externos] cumprir pontualmente as ordens e instruçóes que receber do Professor em tudo o que disser respeito ao curativo dos doentes a seu cargo, entendendo-se nessa obrigação a de sangrarem". ${ }^{16}$

Mesmo assim, o número de pensionistas nunca foi suficiente para dar conta das sangrias que deveriam ser feitas. Até o final do período estudado, a Santa Casa continuava a contratar fornecedores de sanguessugas, que incluíam no serviço as aplicações por sangradores. A administração vivia às voltas com problemas relativos ao não-cumprimento do contrato. Em 1829, chegaram a pensar na "compra de duas máquinas de extrair sangue" para tentar diminuir as despesas com esse item. ${ }^{17}$

Portanto, apesar da diminuição do espaço para atuação dos sangradores, estes ainda tinham de ser tolerados, de preferência, sob supervisão dos empregados do hospital. Este, em conseqüência da maior presença e autoridade dos médicos, passou por várias reformas para se adequar às regras da higiene. As modificações visavam à melhoria da circulação de ar nas enfermarias, mas a aplicação com- 
pleta das recomendações higienistas ocorreu com o projeto, desenvolvido pela Academia Imperial de Medicina, em 1838, e a inauguração do novo hospital da Santa Casa, em 1852. Obedecendo-se às orientações sobre o formato do estabelecimento, a divisão das enfermarias, o tamanho e a localização das janelas, além das observações sobre assoalho, telhas e forro, os médicos garantiriam condiçōes mais propícias à recuperação dos doentes internados. Lançando mão de um recurso caro aos higienistas - a estatística -, os médicos procuravam demonstrar aos leigos a eficácia de suas medidas e atrair pessoas de grupos sociais mais remediados para se tratar no hospital. ${ }^{18}$

\section{Conclusão}

Durante a primeira metade do século XIX, assim como hoje em dia, muitos enfermos procuravam ajuda de terapeutas não-oficializados, que se baseavam em conhecimentos adquiridos de outros mais velhos ou por experiência própria. Outros tantos doentes se automedicavam ou buscavam conselhos com parentes e vizinhos. Num ambiente bem mais restrito e controlado como o hospital, a medicalização desenvolveu-se bastante durante a primeira metade dos Oitocentos. Contudo, de acordo com as reclamações dos próprios médicos a respeito do exercício ilegal da medicina, encontradas em periódicos e teses, as regras de higiene, defendidas pelos acadêmicos, não eram empregadas como estes gostariam fora do âmbito hospitalar. Em seu discurso, culpavam a ignorância ou ingenuidade dos doentes, a ganância dos terapeutas não-oficializados e a falta de controle da situação por parte das autoridades. Dessa forma, podemos perceber que, apesar dos esforços dos médicos em tentar estabelecer o monopólio das atividades de cura e, conseqüentemente, as prescrições higiênicas que defendiam, os terapeutas não-autorizados continuaram a exercer as suas atividades e a população continuava a recorrer a esses últimos, reconhecendo a sua competência para tratar de seus males.

\section{Notas}

1 Este artigo é baseado na minha dissertação de mestrado (Pimenta, 1997) e na pesquisa de doutorado, ambas realizadas no Departamento de História da UniCAmP.

2. Códice 6-1-23, Documentos sobre a escravidão e mercadores de escravos (1777-1831), Arquivo Geral da Cidade do Rio de Janeiro (AGCRJ).

3. Anais da Câmara dos Deputados, sessão de 17 de agosto de 1826. 
4. Freqüentando o curso por mais um ano, o aluno sairia com esse título que lhe permitiria exercitar, igualmente, a cirurgia e a medicina. Lei de 9/9/1826, Coleção de Leis do Brasil.

5. Semanário de Saúde Pública, pela Sociedade de Medicina do Rio de Janeiro, n. 15, 9 de abril de 1831.

6. Leis de 30/8/1828 e de 14/11/1828, Coleção de Leis do Brasil.

7. Registros de Posturas feitas pela Câmara Municipal - Seção $1^{\mathrm{a}}$, título $2^{\circ}$, par. $10^{\circ}$. Códice 49-3-8, AGCRJ.

8. Lei de 3/10/1832, Coleção de Leis do Brasil.

9. Códice 50-1-5 (Sangradores e dentistas), AGCRJ.

10. Códice 50-1-4 (Sangradores), AGCRJ.

11. Francisco de Paula Costa. Algumas reflexóes sobre o charlatanismo em medicina, tese apresentada à Faculdade de Medicina do Rio de Janeiro, em 1841, p. 17.

12. Ver sessões de vendas do Jornal do Commércio, em especial décadas de 1830 a 1850. A pesquisa limita-se a 1855 .

13. Caixa 1195, Fisicatura mor, Arquivo Nacional (AN).

14. 26/8/1827, Atas; 7/9/1831, Ofícios, Arquivo da Santa Casa da Misericórdia do Rio de Janeiro (ASCMRJ). Ver o estudo de Foucault, focado no contexto da Revolução Francesa (Foucault, 1994).

15. 27/1/1832, 27/8/1835, 4/12/1836, Atas, ASCMRJ.

16. Deliberações sobre a clínica cirúrgica, 22/12/1847, Atos do Provedor, AscmrJ. Obrigação reiterada no regimento de 1852 .

17. 27/3 e 25/6/1845, Atas das Conferências; 27/9/1853, Regulamento e Instrução; $2 /$ 8/1829, 1/7/1831, 20/2/1845, Atas; 8/3/1832, Ordens do Provedor, ASCMrJ.

18. 14/8/1825 e 31/8/1828, Atas; Novo Hospital da Santa Casa - 1840, ASCMrJ.

\section{Referências bibliográficas}

CHALHOUB, S. Visões da liberdade: uma história das últimas décadas da escravidão na Corte. São Paulo: Cia das Letras, 1990.

CUNHA, M.C. Negros estrangeiros: os escravos libertos e sua volta à África. São Paulo: Brasiliense, 1985.

FERREIRA, L.O. O nascimento de uma instituição científica: os periódicos médicos da primeira metade do século XIX. 1996. Tese (Doutorado) Departamento de História, Universidade de São Paulo, São Paulo.

GRAHAM, R. Clientelismo e política no Brasil no século XIX. Rio de Janeiro: UFRJ, 1997.

FOUCAULT, M. O nascimento da clínica. 4. ed. Rio de Janeiro: Forense Universitária, 1994. 
HOLANDA, S.B. A herança colonial: sua desagregação. In: HolANDA, S.B. (Org.). História geral da civilização brasileira. 6. ed. São Paulo: Difel, 1982. t.2, v.1.

LUZ, M. Natural, racional, social: razão médica e racionalidade científica moderna. Rio de Janeiro: Campus, 1988.

KARASCH, M. Slave life in Rio de Janeiro, 1808-1850. Princeton, N.J.: Princeton University, 1987.

MACHADO, R. et al. Danação da norma: medicina social e constituição da psiquiatria no Brasil. Rio de Janeiro: Graal, 1978.

PIMENTA, T.S. Artes de curar: um estudo a partir dos documentos da fisicatura mor no Brasil do começo do século XIX. 1997. Dissertação (Mestrado) - Instituto de Filosofia e Ciências Humanas, Universidade Estadual de Campinas, Campinas.

SANTOS FILHO, L. História geral da medicina brasileira. São Paulo: Hucitec; EDUSP, 1977-1991. 2v.

SILVA, M.B.N. Vida privada e quotidiana no Brasil na época de D. Maria e D. João VI. Lisboa: Estampa, 1993.

SLENES, R. Malungu, ngoma vem: África coberta e descoberta no Brasil. Revista USP, São Paulo, n. 12, p. 48-67, 1991-92.

THOMPSON, R. Flash of the spirit. Nova York: First Vintage, 1984. 